\title{
Efficient Ni-Fe layered double hydroxides/ZnO nanostructures for photochemical water splitting
}

\author{
Elfatih Mustafa ${ }^{\text {a, }}$, Aneela Tahira ${ }^{\text {a }}$, Rania E. Adam ${ }^{\text {a }}$, Zafar Hussain Ibupoto ${ }^{\text {b }}$, Sami Elhag ${ }^{\text {a }}$, \\ Magnus Willander ${ }^{\mathrm{a}}$, Omer Nur ${ }^{\mathrm{a}}$ \\ ${ }^{a}$ Department of Science and Technology, Campus Norrköping, Linköping University, SE-601 74, Norrköping, Sweden \\ ${ }^{\mathrm{b}}$ Institute of Chemistry, University of Sindh, 76080, Jamshoro, Pakistan
}

\section{A R T I C L E I N F O}

\section{Keywords:}

$\mathrm{ZnO}$ nanorods

$\mathrm{Ni}-\mathrm{Fe}$ layered double hydroxides

Photochemical water splitting

\begin{abstract}
A B S T R A C T
Zinc oxide ( $\mathrm{ZnO})$ nanostructures are widely investigated for photocatalytic applications but the functional properties are limited by the fast carrier recombination rate, which is an intrinsic property of $\mathrm{ZnO}$. To optimize the recombination rate of $\mathrm{ZnO}$, a study is carried out in which it is covered with $\mathrm{Ni}$-Fe layered double hydroxides and synergistic effects are created which boosted the photocatalytic activity of ZnO. The nanostructured materials are synthesized by the low temperature aqueous chemical growth and electrodeposition methods. These nanostructures are characterized by scanning electron microscopy (SEM) and powder X-ray diffraction (XRD) technique. SEM study has revealed a Ni-Fe LDH coated ZnO NRs. The powder XRD has showed a cubic phase of the Ni-Fe layered double hydroxide on the ZnO NRs having an excellent crystalline quality. The optical characterization has shown low scattering of light for the Ni-Fe LDH coated ZnO NRs sample. The sample prepared with deposition time of $25 \mathrm{~s}$ showed excellent photochemical water splitting properties compared to counter photoanodes in alkaline media. The photo response was highly stable and fast. The incident photon to current conversion efficiency for the photo-anode of $\mathrm{Ni}-\mathrm{Fe}(\mathrm{LDHs}) / \mathrm{ZnO}$ over $25 \mathrm{~s}$ was $82 \%$ at a maximum absorption of $380 \mathrm{~nm}$ compared to the pristine $\mathrm{ZnO}$ NRs which has $70 \%$ at the same wavelength. This study is providing a simple, cost effective, earth abundant and environment friendly methodology for the fabrication of photo-anodes for diverse applications specifically water oxidation and solar radiation driven water splitting.
\end{abstract}

\section{Introduction}

The photochemical production of hydrogen gas is mainly based on three steps: (a) absorption of high-energy photons compared to the energy bandgap of semiconducting material and consequently generating electron-hole pairs within the semiconducting material, (b) excited charge carrier separation and transport in the semiconducting material, and (c) surface reaction among charge carries and water molecules. To allow the successful water splitting, the conduction band of a semiconductor must be at more negative energy position with respect to the reduction potential of hydrogen ions that further results in hydrogen gas and the valence band must be towards more positive energy level than the oxidation of potential of water into oxygen gas. Moreover, the photocatalyst should be stable in aqueous media during the photoirradiation. The efficiency with respect to the production of hydrogen is estimated with the relative number of excited electrons at the interface of the photocatalyst/water for water reduction. The competing process in photochemical water splitting are accompanied by the charge recombination and charge separation process that strongly influence the efficiency of photocatalytic reaction. The charge recombination decreases the number of electron-hole pairs through the emission of light or photon. Numerous photo-catalysts are designed for the photochemical water splitting such as metal oxides, perovskites, oxy-nitrides, and the main factors controlling the photocatalysis activity are successfully recognized [1].

Zinc oxide $(\mathrm{ZnO})$ is widely investigated as a photocatalyst due to its wide bandgap and high electron mobility [2], inexpensive in production and facile fabrication in producing the variety of unique nanostructures such as nanowires/nanorods etc. [3]. One-dimensional morphology such as nanowires/nanorods and nanotubes have unique properties

\footnotetext{
* Corresponding author.

E-mail address: elfatih.mohammed.mustafa@liu.se (E. Mustafa).
} 
(a)

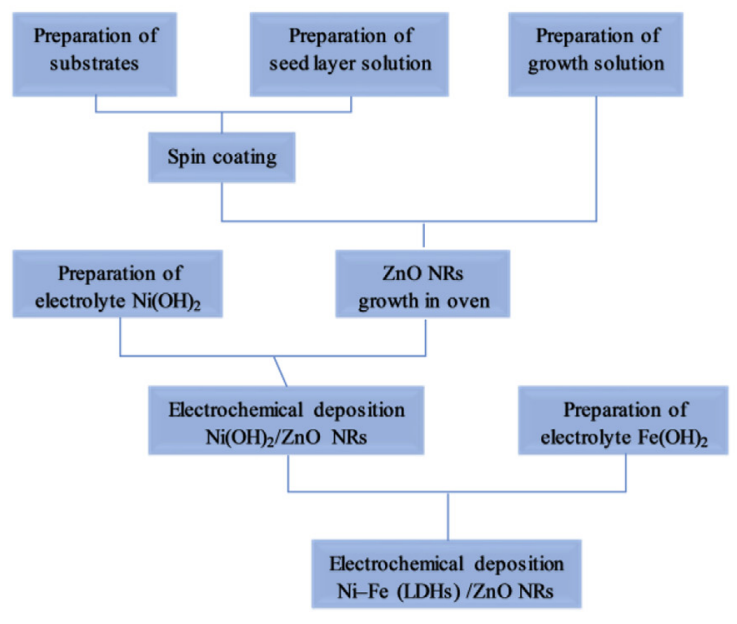

(b)

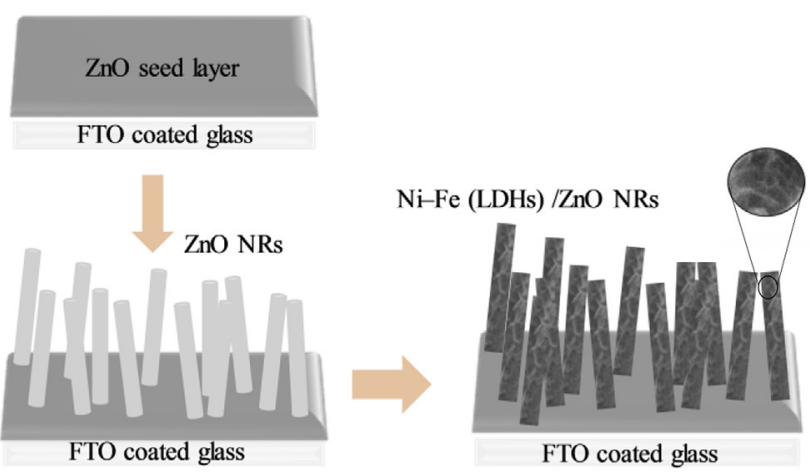

Scheme 1. (a) Synthesis process of the $\mathrm{Ni}-\mathrm{Fe}(\mathrm{LDHs}) / \mathrm{ZnO}$ nanostructures and (b) structure of the Ni-Fe(LDHs)/ZnO nanostructures.

such as high surface area, without sacrificing the geometric area and unidirectional electronic communications that favours fast charge transfer [4]. However, its solar driven efficiency for hydrogen production has challenges due to its high bandgap and plenty of electron-hole recombination possibilities [5]. Also pristine $\mathrm{ZnO}$ has the disadvantage of dissolution into aqueous media during the irradiation of UV light [6]. To minimize the recombination rate of the photo-generated electron hole pairs for pristine $\mathrm{ZnO}$, several strategies are used to modify the chemical composition and surface properties such as ion implantation, doping, dye sensitization [7], or hydrogenation [8], and also the use of composite morphology such as core-shell etc. [9]. In core-shell morphology the inner nanostructure is encapsulated by outer shell of a different material. Also, the hetero-coupling of noble metallic nanomaterials ( $\mathrm{Ag}, \mathrm{Au}, \mathrm{Pd}$, etc.) to $\mathrm{ZnO}$ nanostructures is a widely accepted method to enhance the photocatalytic properties [10-12]. Besides these methods, semiconductor oxides and hydroxides have also been employed to the fabrication of heterostructures with $\mathrm{ZnO}$ nanostructures [13-15]. Moreover, layered double hydroxides (LDHs) have shown promising properties for photocatalysis and are considered the best replacement to $\mathrm{TiO}_{2}$ based photo-catalysts due to their layered structure, flexibility in composition, controlled dimension, low cost, and simple methodologies for preparation [16]. Among the different LDHs, the features of Ni-Fe such as, facile fabrication availability, inexpensive growth, exhibit high specific surface area, high density of the active centers that can facilitate the interaction with different catalytic materials, are highly appealing. Therefore, Ni-Fe (LDHs) might play an active role during coupling with $\mathrm{ZnO}$ and creates a synergistic effect which could remain responsible for superior performance for photochemical water splitting in alkaline media. By harvesting these unique avenues of Ni-Fe layered double hydroxides, and further the deposition of Ni-Fe layered double hydroxide may prevent the dissolution of $\mathrm{ZnO}$ in aqueous solution under light irradiation and results in an efficient photocatalysis. Based on our knowledge, and reported literature there is no report about Ni-Fe layered double hydroxide deposited on $\mathrm{ZnO}$ nanowires/nanorods for photochemical water splitting.

In this work, ZnO NRs and Ni-Fe (LDHs) were designed and successfully synthesized via the combination of facile hydrothermal and electrochemical deposition methods. The ZnO NRs decorated with Ni-Fe layered double hydroxide are characterized by various analytic techniques such as SEM, XRD, and UV-Vis. spectroscopy. Different optimization is carried out in reporting the optimum photocatalyst by considering the thickness of $\mathrm{Ni}$-Fe layered double hydroxide (see Scheme 1).

\section{Experimental}

\subsection{Synthesis of the Ni-Fe layered double hydroxides ( $\mathrm{LDHs}$ )/ZnO nanostructures}

The Ni-Fe (LDHs)/ZnO nanostructures were prepared through three steps: the fabrication of $\mathrm{ZnO} N R s$, the synthesis of $\mathrm{Ni}(\mathrm{OH})_{2} / \mathrm{ZnO}$ heterostructure precursors and $\mathrm{Ni}-\mathrm{Fe}$ (LDHs)/ZnO nanostructures. All chemicals (Sigma-Aldrich) were of analytical reagent grade and were used without any further purification.

\subsection{The fabrication of ZnO NRs on fluorine-doped tin oxide (FTO) glass substrates}

The FTO substrates (surface resistivity $\sim 8 \Omega \mathrm{cm}^{-2}$ and transmittance $80-81.5 \%$ (visible)) used were first ultrasonically cleaned by acetone, isopropanol, and deionized (DI) water respectively each for $5 \mathrm{~min}$ and were then dried up using blowing nitrogen. Then, the FTO substrates were seeded with zinc acetate dehydrate layer via spin coating technique at $2000 \mathrm{rpm}$ for $30 \mathrm{~s}$. The seed solution of $0.01 \mathrm{M}$ zinc acetate dehydrate in $99 \%$ methanol was prepared at constant stirring and heating at $60^{\circ} \mathrm{C}$. A solution of potassium hydroxide $(\mathrm{KOH})$ in methanol $(0.03 \mathrm{M})$ was added dropwise to this solution for a duration of $2 \mathrm{~h}$. This coating step was repeated three times to ensure uniform coverage of the $\mathrm{ZnO}$ seeds. This step was then followed by annealing in a normal laboratory oven for $10 \mathrm{~min}$ at $120^{\circ} \mathrm{C}$. Afterwards, the seed coated substrate were fixed horizontally upside-down in Teflon sample holder and kept in equimolar $0.05 \mathrm{M}$ solution of hexamethylenetetramine (HMT) and zinc nitrate hexahydrate (ZNH). The beaker containing the samples into the growth solution were covered with aluminium foil and placed in preheated laboratory oven at $90^{\circ} \mathrm{C}$ for $5 \mathrm{~h}$. Finally, these samples were rinsed and cleaned with the deionized (DI) water and dried using blowing nitrogen.

\subsection{Preparation of Ni-Fe layered double hydroxides ( $\mathrm{LDHs}$ )/ZnO NRs heterostructure precursors}

The deposition of the Ni-Fe layered double hydroxide onto the $\mathrm{ZnO}$ nanorods was carried out by the electrodeposition by using a $0.15 \mathrm{M}$ equimolar solution of $\mathrm{Ni}\left(\mathrm{NO}_{3}\right)_{2} 6 \mathrm{H}_{2} \mathrm{O}$ and $\mathrm{FeSO}_{4} 6 \mathrm{H}_{2} \mathrm{O}$ in $50 \mathrm{~mL}$ DI water. The precursor solution was saturated with the $\mathrm{N}_{2}$ in order to prevent the oxidation of $\mathrm{Fe}^{2+}$ and the potentiostatic deposition was carried out at a potential of $-1.0 \mathrm{~V}$ (vs $\mathrm{Ag} / \mathrm{AgCl}$ ) at different intervals of times. The grown samples were used as the working electrode, while a platinum sheet was used as counter electrode and finally $\mathrm{Ag} / \mathrm{AgCl}$ was used as a 
a

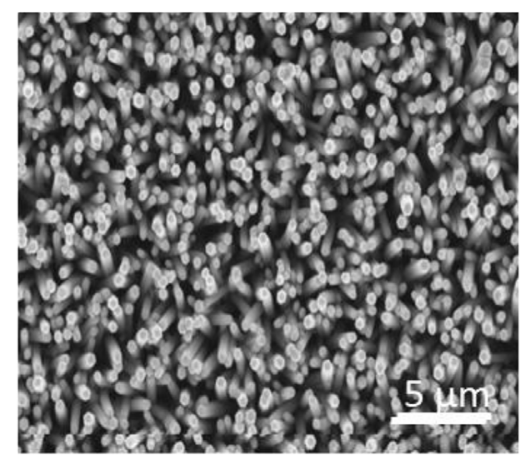

C

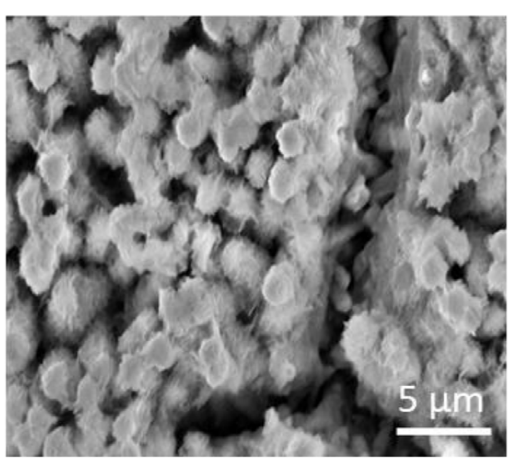

$\mathrm{e}$

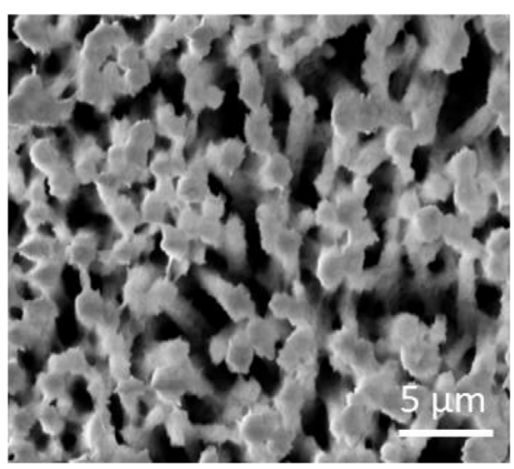

b

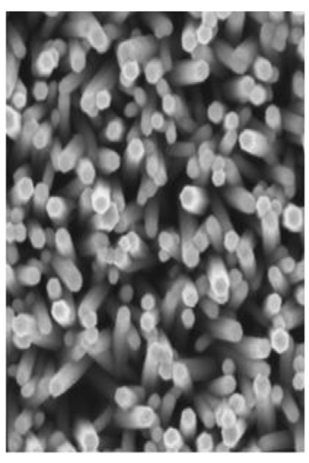

d

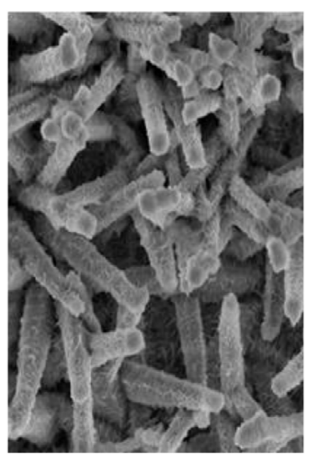

f

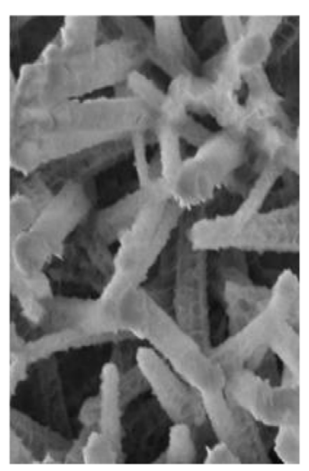

Fig. 1. SEM images of (a, b) Pure ZnO NRs grown on FTO glass substracted at high and low magnification. (c,d) $\mathrm{Ni}-\mathrm{Fe}(\mathrm{LDHs}) / \mathrm{ZnO}$ at $20 \mathrm{~s}$ deposition $(\mathrm{e}, \mathrm{f})$ $\mathrm{Ni}-\mathrm{Fe}(\mathrm{LDHs}) / \mathrm{ZnO}$ at $25 \mathrm{~s}$ deposition at high and low magnifications.

reference electrode respectively (see Scheme 1).

\subsection{Characterization}

The crystal structure and composition of the grown samples were measured by X-ray powder diffraction (XRD) using a Philips PW 1729 powder diffractometer equipped with a $\mathrm{CuK \alpha} \alpha$ radiation source $(\lambda=1.5418 \AA$ ) using a generator voltage of $40 \mathrm{kV}$ and a current of $40 \mathrm{~mA}$. The morphology and structure of the products were characterized by using a field emission scanning electron microscope (FE-SEM Hitachi S4800). The instrument is equipped with an energy-dispersive X-ray spectroscopy (EDX). Optical absorption spectra were obtained by a PerkinElmer Lambda 900 UV-visible spectrophotometer.

\subsection{Photoelectrochemical characterization}

The photoelectrochemical (PEC) measurements (linear sweep voltammetry (LSV), chronoamperometry, and staircase potentio electrochemical impedance spectroscopy (SPEIS)) were carried out on an SP-200 potentiostat (Bio-Logic, Claix, France). A conventional three electrodes configuration was used with working electrode, a platinum sheet as the counter electrode and a standard $\mathrm{Ag} / \mathrm{AgCl}$ as a reference electrode in $3 \mathrm{M} \mathrm{KCl}$ solution. The electrolyte used was $1 \mathrm{M} \mathrm{KOH}$ aqueous solution. The LSV was carried out at a scan rate of $0.1 \mathrm{~V} / \mathrm{s}$. Chronoamperometry I- $t$ curves were tested at a bias voltage of $0.5 \mathrm{~V}$ (vs Ag/ $\mathrm{AgCl}$ ). The SPEIS was performed at an amplitude of $20 \mathrm{mV}$, in a frequency range of $5 \mathrm{kHz}-0.1 \mathrm{~Hz}$, and at a potential range of $-1.0 \mathrm{~V}$ to $+1.0 \mathrm{~V}$. The working electrodes were illuminated from the front side of the samples by using a solar simulator (LCS-100, Newport, model 94011A). The solar simulator uses a $100 \mathrm{~W}$ ozone free xenon lamp and includes an AM 1.5G air mass filter with an output power of 1 Sun (AM 1.5G). The total area of the photo-electrode was $2 \mathrm{~cm} \times 1 \mathrm{~cm}$, while the light is illuminated on a $1 \mathrm{~cm} \times 1 \mathrm{~cm}$ that was immersed in the electrolyte. In order to estimate the wavelength dependent efficiency i.e. the incident photon-to-current conversion efficiency (IPCE), a monochromator (Oriel model 74125) fitted with a $300 \mathrm{~W}$ xenon lamp was used. The spectra were recorded in a wavelength range of $250-700 \mathrm{~nm}$ with an interval of $10 \mathrm{~nm}$.

\section{Results and discussion}

The morphological features were investigated by scanning electron microscopy as depicted in Fig. 1. Fig. 1 a and b show a hexagonal facets structure of $\mathrm{ZnO}$ NRs as expected. However, the deposition of the Ni-Fe layered double hydroxide on the $\mathrm{ZnO}$ NRs indicates that the $\mathrm{Ni}-\mathrm{Fe}$ LDH has coated ZnO NRs as depicted in Fig. 1 c-f. The layer thickness is not increased significantly for longer deposition durations. Furthermore, EDX of the samples Fig. 2 shows the abundance of different elements in the samples. The atomic ratios of iron and nickel compared to $\mathrm{Zn}$ are 0.164 and 0.132 , respectively.

XRD study was carried out for the ZnO sample and the measured diffraction patterns of the (100), (002), (101), (102), (110), (103), (200), (112), and (201) planes are observed at diffraction angles of $32.7^{\circ}, 34.5^{\circ}$, $36.42^{\circ}, 47.44^{\circ}, 56.58^{\circ}, 63.2^{\circ}, 66.76^{\circ}, 67.86^{\circ}$ and $69.0^{\circ}$, respectively. They are attributed to the wurtzite structure of $\mathrm{ZnO}$. In the case of the Ni$\mathrm{Fe}(\mathrm{LDHs})$ deposited on $\mathrm{ZnO}$ extra peaks showing the crystal planes (003), (012), (015), and (113) at $10.2^{\circ}, 32.0^{\circ}, 38.1^{\circ}$, and $61.7^{\circ}$ diffraction angles are observed, respectively (see Fig. 3). These diffraction patterns are well matched to the hydrotalcite phase of LDHs and are in good agreement with other reported works [17-19].

The optical characterization of the samples was carried out by UV-Visible spectroscopy. The UV-Vis spectra of the FTO, pure ZnO NRs, $\mathrm{Ni}-\mathrm{Fe}(\mathrm{LDHs}) / \mathrm{ZnO}$ at $20 \mathrm{~s}$ deposition, and $\mathrm{Ni}-\mathrm{Fe}(\mathrm{LDHs}) / \mathrm{ZnO}$ at $25 \mathrm{~s}$ deposition are enclosed in Fig. 4 and light scattering is heavily noticed for the pure $\mathrm{ZnO}$ as shown in Fig. 4. While low scattering is found for the Ni-Fe LDH coated ZnO NRs. This study further supports the SEM results indicating that successful deposition of layered double hydroxide has been achieved.

The photoelectrochemical response of various photo-anodes was measured in $1 \mathrm{M} \mathrm{KOH}$ solution having a $\mathrm{pH} 14$. Fig. 5a shows the LSV response for pure $\mathrm{ZnO} \mathrm{NRs}, \mathrm{Ni}-\mathrm{Fe}(\mathrm{LDHs}) / \mathrm{ZnO}$ at $20 \mathrm{~s}$ deposition, and $\mathrm{Ni}-\mathrm{Fe}(\mathrm{LDHs}) / \mathrm{ZnO}$ at $25 \mathrm{~s}$ deposition. Importantly, in dark the response of photo-anodes is very weak and requires more potential for water oxidation. However, with illumination of 1 Sun (AM 1.5G) of light there is a drastic decrease in the redox potential of water, still higher potential is required which is due to the fact part of energy is required for the oxidation provided by the light. The Ni-Fe layered double hydroxide/ $\mathrm{ZnO}$ showed the maximum response and the lowest redox potential for water oxidation that could be assigned to the tuned properties of $\mathrm{ZnO}$ after the deposition of the Ni-Fe layered double hydroxide that created the chemical coupling and the synergistic effects during the chemical growth. Fig. 5b shows the photocurrent response under the illumination and dark conditions. The photo response is fast and stable and the photoanode of Ni-Fe layered double hydroxide with deposition of $25 \mathrm{~s}$ is giving the highest photocurrent and stable response due to relatively high 


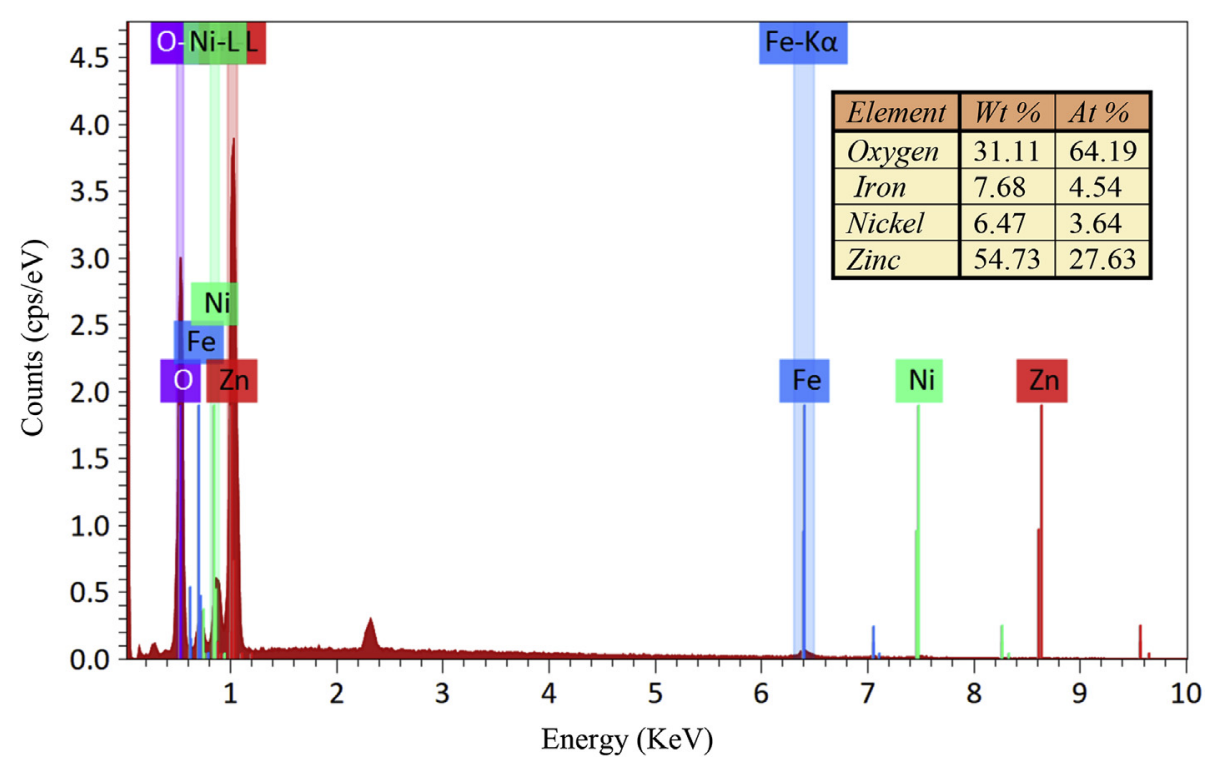

Fig. 2. EDX spectra for $\mathrm{Ni}-\mathrm{Fe}(\mathrm{LDHs}) / \mathrm{ZnO}$ at $25 \mathrm{~s}$ deposition.

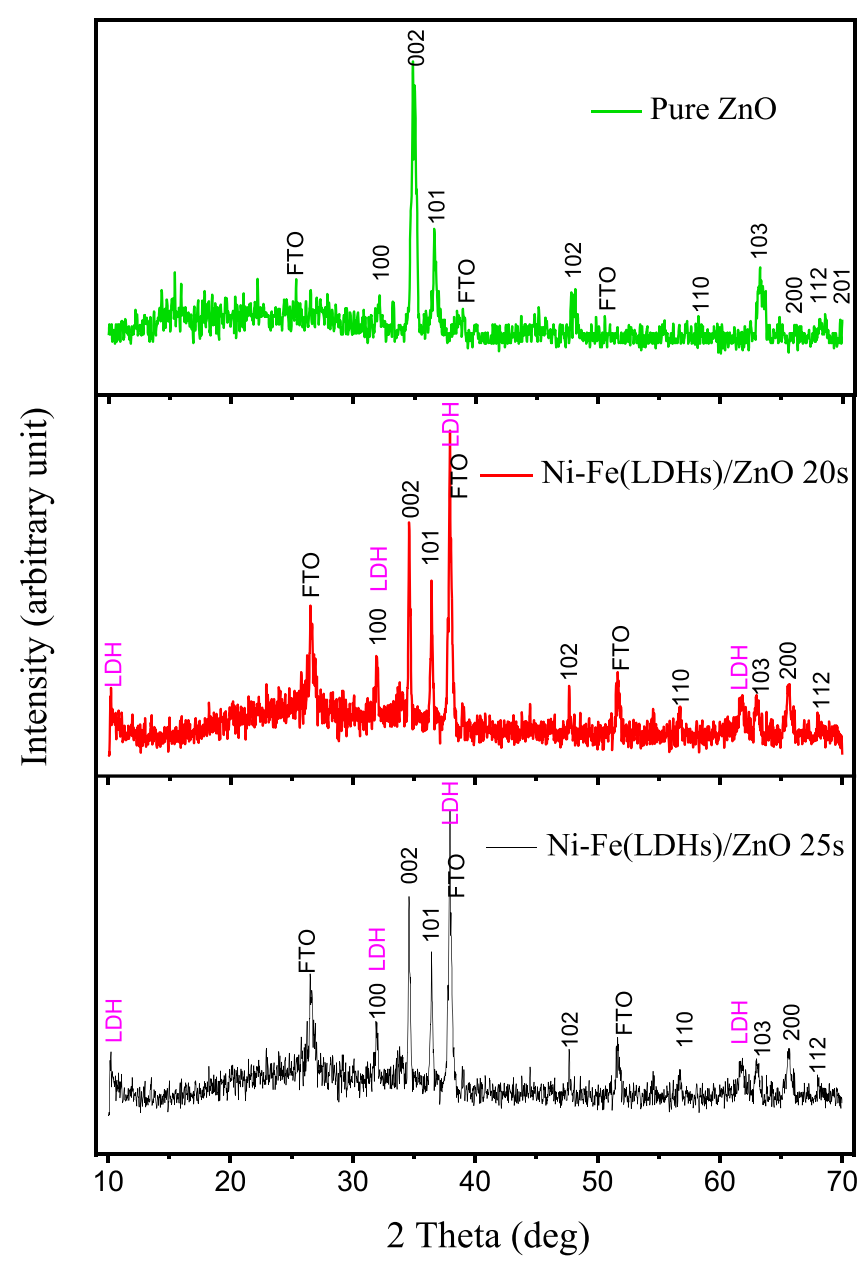

Fig. 3. $\mathrm{XRD}$ patterns of pure $\mathrm{ZnO}$, and $\mathrm{Ni}-\mathrm{Fe}(\mathrm{LDHs}) / \mathrm{ZnO}$ heterostructures.

photocatalytic activity of the hybrid material. The interface between the electrolyte and electrodes of pure $\mathrm{ZnO}$ NRs and the $\mathrm{Ni}-\mathrm{Fe}(\mathrm{LDHs}) / \mathrm{ZnO}$ $25 \mathrm{~s}$ was investigated using the Mott-Schottky method. From the

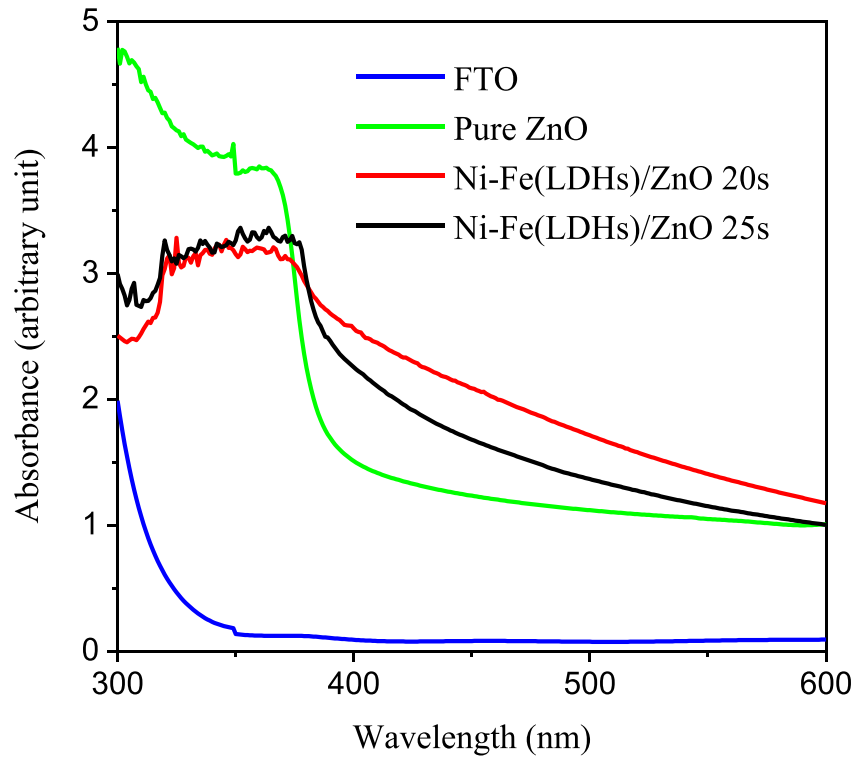

Fig. 4. The optical absorbance of FTO, pure $\mathrm{ZnO} n \mathrm{NRs}, \mathrm{Ni}-\mathrm{Fe}(\mathrm{LDHs}) / \mathrm{ZnO} 20 \mathrm{~s}$, and $\mathrm{Ni}-\mathrm{Fe}(\mathrm{LDHs}) / \mathrm{ZnO} 25 \mathrm{~s}$.

intercept of Fig. 6 , and at a selected frequency $(\sim 1 \mathrm{kHz})$, the extracted values for the flat band potential $\left(V_{\mathrm{fb}}\right)$ for using the electrodes of pure $\mathrm{ZnO}$ NRs and $\mathrm{Ni}-\mathrm{Fe}(\mathrm{LDHs}) / \mathrm{ZnO} 25$ seconds are $\sim-0.57 \mathrm{~V}$ and $\sim$ $-0.65 \mathrm{~V}$ (vs Ag/AgCl), respectively. A $0.08 \mathrm{~V}$ shift to higher values upon deposition suggests that a higher Fermi level $\left(E_{F}\right)$ could be obtained by deposition. From the slope of the Mott-Schottky plot, the doping densities were found to be $5.9 \times 10^{20} \mathrm{~cm}^{-3}$ and $36.3 \times 10^{20} \mathrm{~cm}^{-3}$ for the pure $\mathrm{ZnO}$ NRs and the $\mathrm{Ni}-\mathrm{Fe}(\mathrm{LDHs}) / \mathrm{ZnO} 25 \mathrm{~s}$, respectively. It is clear that the charge carrier density of the $\mathrm{Ni}-\mathrm{Fe}(\mathrm{LDHs}) / \mathrm{ZnO}$ over $25 \mathrm{~s}$ is the highest, which should contribute to its relatively better PEC activity under visible light.

The incident monochromatic photon to current conversion efficiency (IPCE) is plotted as a function of the excitation wavelength. This was obtained from the photocurrent density recorded at different wavelengths using the formula: 

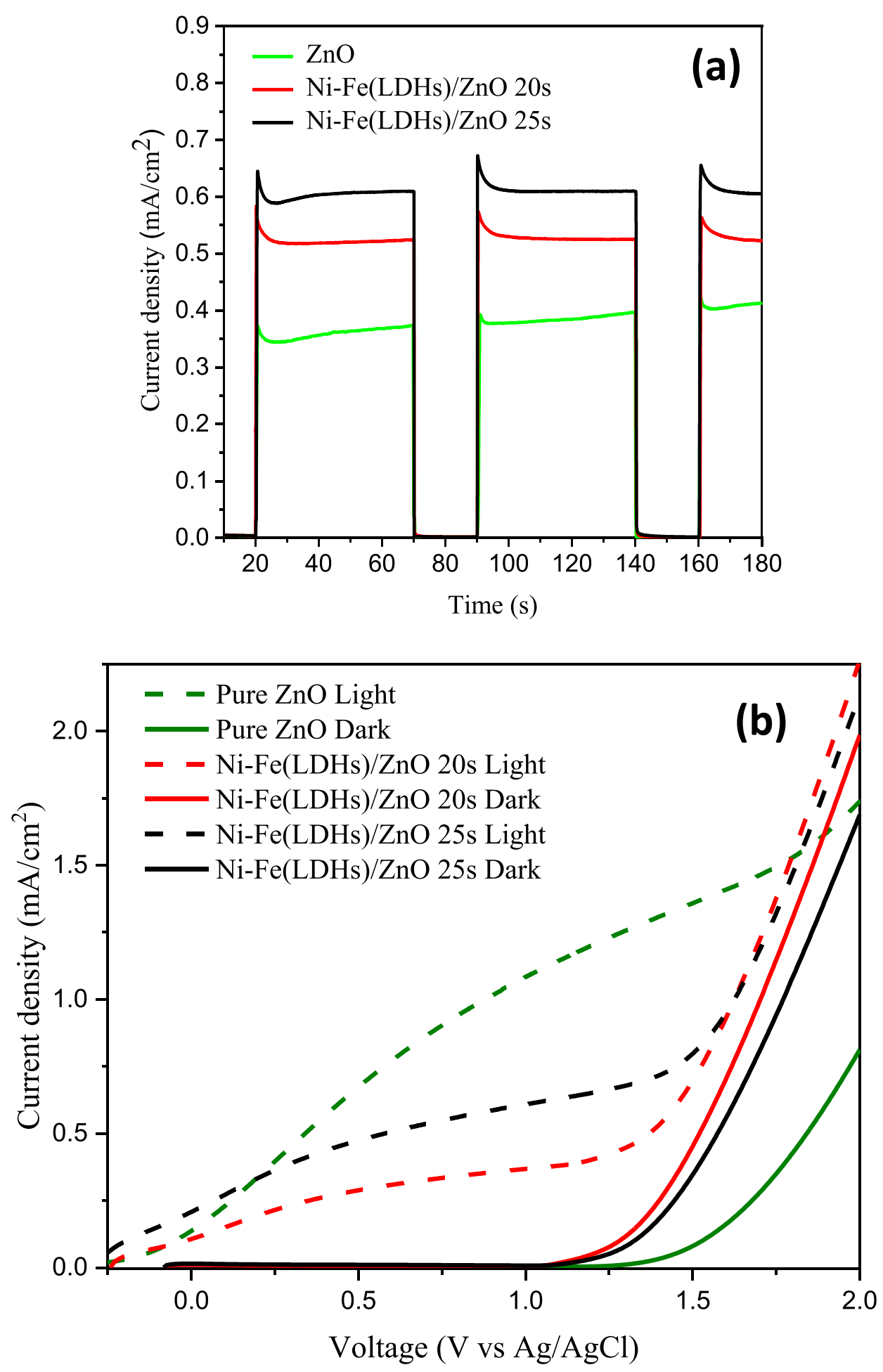

Fig. 5. (a) The I-V curve of pure $\mathrm{ZnO}$ NRs, Ni-Fe(LDHs)/ZnO 20s, and Ni-Fe(LDHs)/ZnO 25s under the illumination of light and dark and (b) Photo response pure ZnO NRs, Ni-Fe(LDHs)/ZnO 20s, and Ni-Fe(LDHs)/ZnO 25s.

$\mathrm{IPCE} \%=\frac{1240 \times J_{p h}}{\lambda \times J_{\text {light }}} \times 100$

where $J_{p h}$ is the photocurrent density, $\lambda$ is the incident wavelength and $J_{\text {light }}$ is the incident irradiance. Fig. 7 compares the IPCE action spectra for the pure $\mathrm{ZnO} \mathrm{NRs}$ and the $\mathrm{Ni}-\mathrm{Fe}(\mathrm{LDHs}) / \mathrm{ZnO}$ at the electrodes after $25 \mathrm{~s}$. It is clear from the figure that the IPCE for the photo-anode of $\mathrm{Ni}-\mathrm{Fe}(\mathrm{LDHs}) / \mathrm{ZnO}$ at $25 \mathrm{~s}$ is increased to $82 \%$ at the maximum wavelength of $380 \mathrm{~nm}$ compared to the pristine $\mathrm{ZnO}$ NRs which is $70 \%$ at the same wavelength.

\section{Conclusions}

In this study, both the low temperature aqueous chemical growth and the electrodeposition methods were used to develop efficient photoanodes based on Ni-Fe layered double hydroxide. ZnO NRs are covered by the Ni-Fe layered hydroxide and resulted in a Ni-Fe LDH coated ZnO NRs as confirmed by SEM. The XRD results revealed the existence of the 


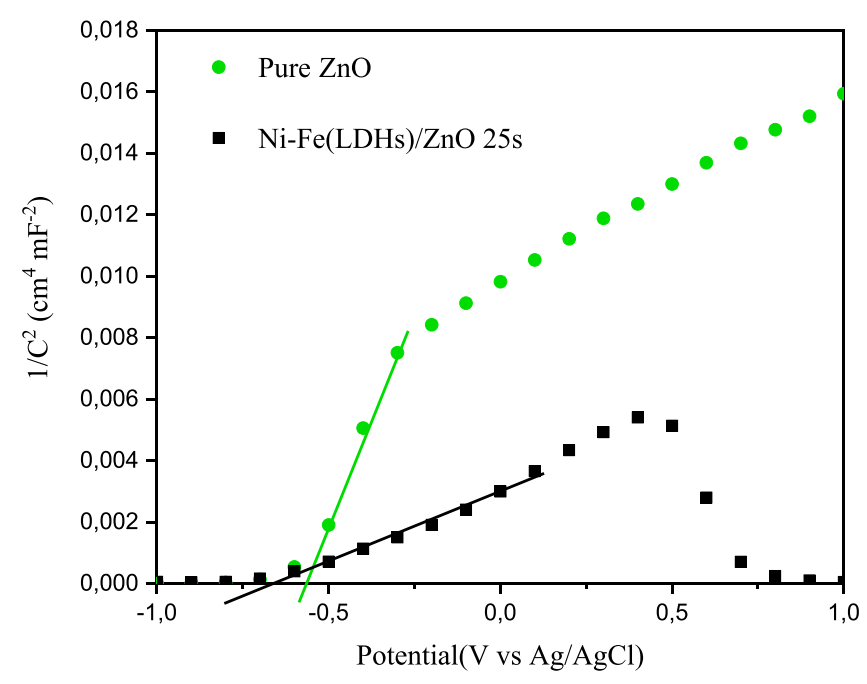

Fig. 6. Mott-Schottky plots for pure ZnO NRs and Ni-Fe(LDHs)/ZnO 25s electrodes in $1 \mathrm{M} \mathrm{KOH}$ solution of $\mathrm{pH} 14$ (at the normal laboratory light conditions) at $1 \mathrm{kHz}$.

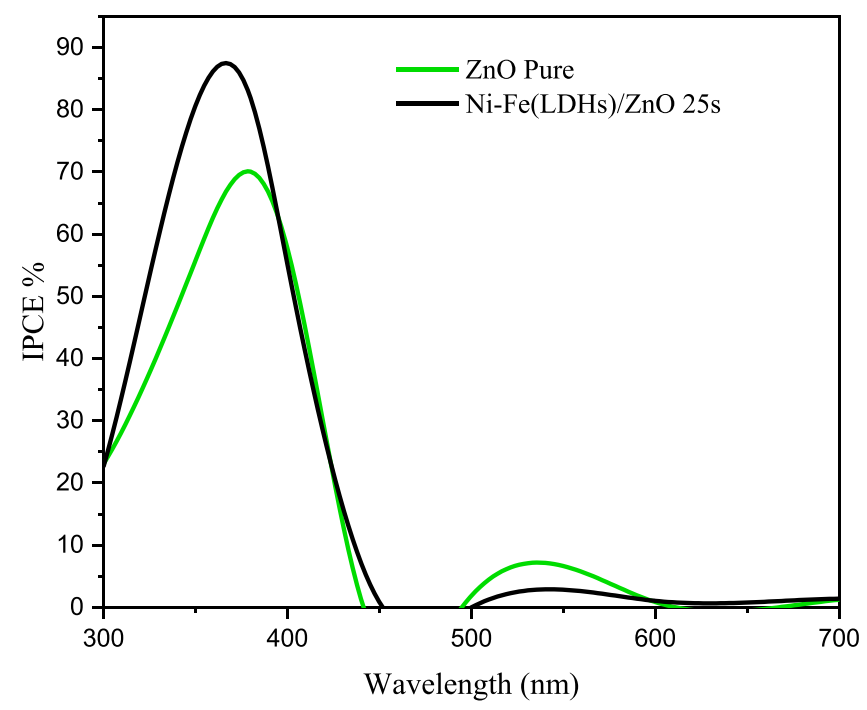

Fig. 7. The incident-photon-current-conversion efficiency (IPCE) of pure $\mathrm{ZnO}$ $\mathrm{NRs}$ and $\mathrm{Ni}-\mathrm{Fe}(\mathrm{LDHs}) / \mathrm{ZnO}$ after a duration of $25 \mathrm{~s}$ in a wavelength range between 300 and $700 \mathrm{~nm}$.

Ni-Fe layered double hydroxide on the ZnO NRs. The optical study has shown that lower light scattering is experienced by the composite nanostructures compared to the pristine ZnO NRs. The ZnO NRs covered with Ni-Fe layered double hydroxides at $25 \mathrm{~s}$ deposition are efficient and stable for water oxidation. The IPCE for the photo-anode of $\mathrm{Ni}-\mathrm{Fe}(\mathrm{LDHs}) / \mathrm{ZnO}$ after $25 \mathrm{~s}$ was found to reach a maximum of $82 \%$ at of $380 \mathrm{~nm}$ compared to the pristine $\mathrm{ZnO}$ NRs which showed $70 \%$ at the same wavelength. The reported values in terms of the stability and photocurrent are attractive and provide a new directions for the fabrication of stable and durable photo-catalysts. This study provides a facile approach for the fabrication of photo anodes which can be capitalized for large scale water oxidation and other photochemical applications.

\section{Acknowledgment}

The authors acknowledge the department of Science and Technology, Campus Norrköping, Linköping University, Sweden for partial financial support.

\section{References}

[1] A.A. Ismail, D.W. Bahnemann, Photochemical splitting of water for hydrogen production by photocatalysis: A review, Sol. Energy Mater. Sol. Cells 128 (2014) 85-101.

[2] C. Bauer, G. Boschloo, E. Mukhtar, A. Hagfeldt, Electron injection and recombination in Ru(dcbpy) ${ }_{2}(\mathrm{NCS})_{2}$ sensitized nanostructured ZnO, J. Phys. Chem. B 105 (2001) 5585-5588.

[3] D. Fattakhova-Rohlfing, A. Zaleska, T. Bein, Three-dimensional titanium dioxide nanomaterials, Chem. Rev. 114 (2014) 9487-9558.

[4] A. Wolcott, J.Z. Zhang, On Solar Hydrogen \& Nanotechnology ch.15, JohnWiley\&Sons, Ltd, 2010, pp. 459-505.

[5] C. Xiaobo, S.M. Samuel, Titanium dioxide nanomaterials: synthesis, properties, modifications, and applications, Chem. Rev. 107 (2007) 2891-2959.

[6] T.P. Chou, Q. Zhang, G. Cao, Effects of dye loading conditions on the energy conversion efficiency of $\mathrm{ZnO}$ and $\mathrm{TiO}_{2}$ dye-sensitized solar cells, J. Phys. Chem. C 111 (2007) 18804-18811.

[7] G. Wang, Y. Ling, H. Wang, L. Xihong, Y. Li, Chemically modified nanostructures for photoelectrochemical water splitting, J. Photochem. Photobiol. C Photochem. Rev. 19 (2014) 35-51.

[8] C. Xu, Y. Song, L. Lu, C. Cheng, D. Liu, X. Fang, X. Chen, X. Zhu, D. Li, Electrochemically hydrogenated $\mathrm{TiO}_{2}$ nanotubes with improved photoelectrochemical water splitting performance, Nanoscale Res. Lett. 8 (2013) 391.

[9] S. Hernandez, D. Hidalgo, A. Sacco, A. Chiodoni, A. Lamberti, V. Cauda, E. Tresso, G. Saracco, Comparison of photocatalytic and transport properties of $\mathrm{TiO}_{2}$ and $\mathrm{ZnO}$ nanostructures for solar-driven water splitting, Phys. Chem. Chem. Phys. 17 (2015) 7775-7786.

[10] Y. Zheng, L. Zheng, Y. Zhan, X. Lin, Q. Zheng, K. Wei, Ag/ZnO heterostructure nanocrystals: synthesis, characterization, and photocatalysis, Inorg. Chem. 46 (2007) 6980-6986.

[11] L. Shen, N. Bao, K. Yanagisawa, Y. Zheng, K. Domen, A. Gupta, C. Grimes, Direct growth of comet-like superstructures of $\mathrm{Au}-\mathrm{ZnO}$ submicron rod arrays by solvothermal soft chemistry process, J. Solid State Chem. 180 (2007) 213-220.

[12] C. Liewhiran, S. Phanichphant, Doctor-bladed thick films of flame-made Pd/ZnO nanoparticles for ethanol sensing, Curr. Appl. Phys. 8 (2008) 336-339.

[13] J. Wang, C. Lee, Y. Chen, C. Chen, Y. Chen, C. Lin, Y. Chen, Double side electroluminescence from $\mathrm{p}-\mathrm{NiO} / \mathrm{n}-\mathrm{ZnO}$ nanowire heterojunctions, Appl. Phys. Lett. 95 (2009) 131117.

[14] N. Wu, M. Zhao, J.G. Zheng, C. Jiang, B. Myers, S. Li, M. Chyu, Porous CuO-ZnO nanocomposite for sensing electrode of high-temperature CO solid-state electrochemical sensor, S.X. Mao. Nanotechnol. 16 (2005) 2878-2881.

[15] X. Cai, Y. Cai, Y. Liu, S. Deng, Y. Wang, Y. Wang, I. Djerdj, Photocatalytic degradation properties of $\mathrm{Ni}(\mathrm{OH})_{2}$ nanosheets/ZnO nanorods composites for azo dyes under visible-light irradiation, Ceram. Int. 40 (2014) 57-65.

[16] Y. Zhao, X. Jia, G. Waterhouse, L. Wu, C. Tung, D. O'Hare, T. Zhang, Layered double hydroxide nanostructured photocatalysts for renewable energy production, Adv. Energy Mater. 6 (2016), 1501974.

[17] F. Wang, T. Wang, S. Sun, Y. Xu, R. Yu, H. Li, One-step synthesis of Nickle Iron layered double hydroxide/reduced graphene oxide/carbon nanofibers composite as electrode materials for asymmetric supercapacitor, Sci. Rep. 8 (2018) 8908.

[18] P. Huang, C. Cao, Y. Sun, S. Yang, F. Wei, W. Song, One-pot synthesis of sandwichlike reduced graphene oxide@CoNiAl layered double hydroxide with excellent pseudocapacitive properties, J. Mater. Chem. 3 (2015) 10858.

[19] X. Cai, X. Shen, L. Ma, Z. Ji, C. Xu, A. Yuan, Solvothermal synthesis of NiCo-layered double hydroxide nanosheets decorated on RGO sheets for high performance supercapacitor, Chem. Eng. J. 268 (2015) 251-259. 